\title{
Social embeddedness as a mechanism for linking social cohesion to well-being among older adults: moderating effect of gender
}

This article was published in the following Dove Press journal:

Clinical Interventions in Aging

26 May 2014

Number of times this article has been viewed

\author{
Yadollah Abolfathi Momtaz' \\ Sharifah Azizah Haron ${ }^{2}$ \\ Rahimah Ibrahim ${ }^{3}$ \\ Tengku Aizan Hamid ${ }^{3}$ \\ 'Institute of Gerontology, Universiti \\ Putra Malaysia, Serdang, Selangor, \\ Malaysia; ${ }^{2}$ Institute of Gerontology, \\ Department of Resource Management \\ and Consumer Studies, Faculty \\ of Human Ecology, Universiti \\ Putra Malaysia, Serdang, Selangor, \\ Malaysia; ${ }^{3}$ Institute of Gerontology, \\ Department of Human Development \\ and Family Studies, Faculty of Human \\ Ecology, Universiti Putra Malaysia, \\ Serdang, Selangor, Malaysia
}

Background: The positive effect of social cohesion on well-being in older adults has been well documented. However, relatively few studies have attempted to understand the mechanisms by which social cohesion influences well-being. The main aim of the current study is to identify social pathways in which social cohesion may contribute to well-being.

Methods: The data for this study (taken from 1,880 older adults, aged 60 years and older) were drawn from a national survey conducted during 2008-2009. The survey employed a two-stage stratified sampling process for data collection. Structural equation modeling was used to test mediating and moderating analyses.

Results: The proposed model documented a good fit to the data (GFI $=98$; CFI $=0.99$; RMSEA =0.04). The findings from bootstrap analysis and the Sobel test revealed that the impact of social cohesion on well-being is significantly mediated by social embeddedness $(Z=5.62$; $P<0.001)$. Finally, the results of a multigroup analysis test showed that social cohesion influences well-being through the social embeddedness mechanism somewhat differently for older men than women.

Conclusion: The findings of this study, in addition to supporting the importance of neighborhood social cohesion for the well-being of older adults, also provide evidence that the impact of social cohesion towards well-being is mediated through the mechanism of social embeddedness.

Keywords: aged, social embeddedness, social cohesion, well-being

\section{Introduction}

Like other countries, Malaysia has an aging population due to increased life expectancy and decreased fertility rates. ${ }^{1}$ While the continuing increase in life expectancy represents a triumph of medical, social, and economic advances - and should be a matter for congratulations - it also poses the challenge of maintaining the health and wellbeing of older adults. ${ }^{2}$ In light of the emphasis on well-being of older adults, research on factors that can maintain and improve well-being in old age has become of greater importance. Review of the gerontological research shows that most preceding studies have focused on the impact of individual characteristics influencing the well-being of older adults. ${ }^{3}$ In view of the fact that older adults spend more time in their homes, it is possible to expect that they are influenced by their neighborhood surroundings. ${ }^{2,4}$

Social cohesion, as the cognitive component of social capital, has been conceptualized as levels of mutual trust, norms of reciprocity, shared values, and solidarity among neighbors. ${ }^{5-7}$ It has also been described as "the glue that bonds society together, promoting harmony, a sense of community, and a degree of commitment to promoting common good". 8
Correspondence: Sharifah Azizah Haron Institute of Gerontology, Universiti Putra Malaysia, 43400 UPM, Serdang, Selangor, Malaysia

Email sh.azizah@upm.edu.my 
The findings of previous studies show statistically significant associations between perceived neighborhood social cohesion and higher self-rated health, ${ }^{4,9}$ lower mortality rate, ${ }^{10,11}$ and lower levels of depressive symptoms. ${ }^{12-14}$ However, relatively few studies have attempted to understand mechanisms through which social cohesion could affect wellbeing. Recent studies have suggested the need to inquire into pathways through which neighborhood social cohesion could influence health and well-being. ${ }^{10,15,16}$

It is assumed that social cohesion may contribute to higher levels of well-being in older adults through a pathway that leads to higher degrees of social organization, including provision of support to neighbors in times of sickness, and help, which may consequently contribute to better outcomes of well-being. ${ }^{2,15}$

The main purpose of the present study was to identify social pathways by which social cohesion is related to wellbeing. In addition - since it has been documented that women (compared with men) tend to maintain more emotionally intimate relationships, provide more social support to others, and are substantially benefited by emotional social support against major depression ${ }^{17-19}$ - it was hypothesized that effects of social cohesion on well-being differ between gender. Therefore, further analysis was conducted to determine whether the path coefficients for the relationships between social cohesion to well-being are significantly moderated by gender.

\section{Theoretical model}

The influence of neighborhood conditions on health can be classified into three types. The first type is related to the physical characteristics of the environment (eg, environmental pollution), which directly affect the individual health of residents. The next condition - that neighborhood may affect health - pertains to neighborhood socioeconomic conditions, such as community services and facilities, which affect health. ${ }^{15,20}$ The third condition - which several studies have found significantly to positively contribute to health and well-being - is social condition in the neighborhood. However, relatively few studies have attempted to elucidate the mechanisms through which social condition in the neighborhood affects well-being.

This study aimed to explore social embeddedness as a potential mechanism linking the neighborhood's social cohesion to well-being. Social embeddedness refers to connections that individuals maintain with other people in their social environment. It is assumed that the presence of social connections ensures that support is being provided. ${ }^{21}$ A more socially-cohesive neighborhood leads to higher levels of social embeddedness, ${ }^{22,23}$ thought to lead to supportive interpersonal connections at the individual level (including greater tangible and emotional support), which may contribute to higher levels of well-being. ${ }^{12}$ Figure 1 shows the proposed theoretical model.

Based on the proposed theoretical model, the following hypotheses were tested:

1. Social cohesion is significantly associated with older adults' well-being.

2. The social embeddedness mechanism significantly mediates the impact of social cohesion on well-being, through tangible support and emotional support.

3. The association between social cohesion and well-being is moderated by gender.

\section{Methodology}

The data for this study were obtained from a national survey, conducted during 2008-2009, entitled "Patterns of social relationships and psychological well-being among older persons in peninsular Malaysia". ${ }^{24}$ The survey employed a two-stage, geographically clustered sampling method to produce a nationally representative sample of older Malaysians. A total of 2,350 households were sampled, with only one older person interviewed from each selected household. Each faceto-face interview was conducted in the respondent's home.

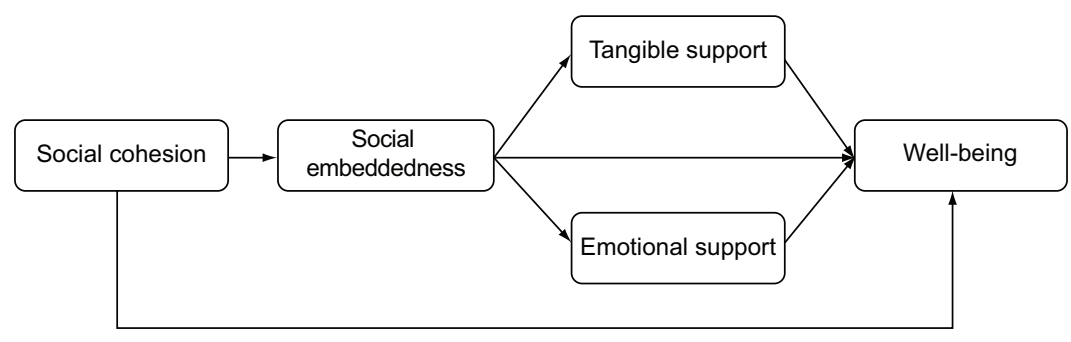

Figure I The proposed theoretical model linking social cohesion and well-being.

Note: According to this model, a cohesive neighborhood may induce more supportive interpersonal connections, which provide tangible and emotional support that consequently contribute to higher levels of well-being. 
Data were collected on the socioeconomic and health status of adults aged 60 years and older. The completed interviews involved a total of 1,880 older persons, with an overall response rate of $80 \%$. Details of the methodology have been published elsewhere. ${ }^{25}$

\section{Measures}

\section{Social cohesion}

Social cohesion was measured using a five-item instrument developed by Sampson et al. ${ }^{26}$ These items included: 1) People around here are willing to help their neighbors; 2) This is a close-knit neighborhood; 3) People in this neighborhood can be trusted; 4) People in this neighborhood generally do not get along with each other; and 5) People in my neighborhood do not share the same values. The respondents were asked on a five-point scale to score how strongly they agreed with each statement ( $1=$ strongly disagree; $5=$ strongly agree). All five items were added, to produce a total score. Higher total scores indicate that respondents perceive their neighborhood to be more cohesive. In the present study, social cohesion measurement demonstrated very good internal consistency (Cronbach's alpha $[\alpha]=0.89$ ).

\section{Well-being}

The WHO Well-Being Index (WHO-5) - a psychometricallysound, five-item measure of well-being - was used to assess well-being. ${ }^{27}$ This instrument has shown good reliability and validity among older Malaysians. ${ }^{25}$ All five items are rated, based on a six-point Likert scale. The total score is computed from the sum of all five items, and is then transformed into a scale value between $0-100$. A higher score indicates higher levels of well-being. ${ }^{28}$ In the current study, WHO-5 demonstrated very good internal consistency $(\alpha=0.87)$.

\section{Social embeddedness}

Social embeddedness has been defined as the frequency of contact with those in one's social network. ${ }^{21,29}$ In the current study, social embeddedness was measured by the Lubben Social Network Scale - 6, a six-item, self-reported scale, with a total score range between $0-30$. This scale demonstrated an acceptable internal consistency for this sample $(\alpha=0.81)$.

\section{Tangible support}

In this study, tangible support was measured using four items taken from the Medical Outcomes Study Social Support Survey (MOS-SSS). ${ }^{30}$ These items include: 1) Someone to help you if you were confined to bed; 2) Someone to take you to the doctor if you needed it; 3) Someone to prepare your meals if you were unable to do it yourself; 4) Someone to help with daily chores if you were sick. The total score was obtained from the sum of all four items, and ranges between $1-16$. The scale indicated an excellent internal consistency for this study ( $\alpha=0.93)$.

\section{Emotional support}

Emotional support was measured by averaging respondents' responses to the four-item scale of emotional/informational support developed in the MOS-SSS. ${ }^{30}$ These items were as follows: 1) Someone you can count on to listen to you when you need to talk; 2) Someone to confide in or talk to about yourself or your problems; 3) Someone to share your most private worries and fears with; 4) Someone who understands your problems. The total score for emotional support was computed by adding all four items, and ranges between 1-16. Higher scores indicate higher levels of emotional support. This scale demonstrated excellent internal consistency in the current study $(\alpha=0.92)$.

\section{Ethical considerations}

The study was ethically conducted in accordance with the Declaration of Helsinki of the World Medical Association, and was approved by the Ethics Committee of the Ministry of Science, Technology and Innovation, Malaysia. Verbal informed consent was obtained from all respondents, after explanation of the study's objectives.

\section{Data analysis}

Descriptive statistics, Cronbach's alpha coefficients, and zero-order correlations between measurement variables were analyzed using SPSS version 21 statistical software (IBM Corporation, Armonk, NY, USA). Structural equation modeling (SEM), using SPSS Amos version 21 software (IBM Corporation), was performed to test the mediation model. The overall model fit was examined using the chi-square test $\left(\chi^{2}\right)$, comparative fix index (CFI), and the root mean square error of approximation (RMSEA). A bootstrapping method was used to test statistical significance of mediation with all mediators in the model. ${ }^{31}$ The Sobel test ${ }^{32}$ was also used to make conclusions about the statistical significance of individual mediators. Finally, a multigroup analysis was performed to examine whether the mediation model is moderated by gender.

\section{Results}

The mean age of the respondents was 69.79 years (standard deviation: 7.36 years); $52.6 \%$ were female and $56.2 \%$ were 
Table I Means, standard deviations, and zero-order correlations between study variables

\begin{tabular}{|c|c|c|c|c|c|}
\hline Variable & $\mathbf{I}$ & 2 & 3 & 4 & 5 \\
\hline \multicolumn{6}{|l|}{ I) Social cohesion } \\
\hline 2) Social embeddedness & $0.240 * *$ & & & & \\
\hline 3) Tangible support & $0.164 * *$ & $0.160 * *$ & & & \\
\hline 4) Emotional support & $0.265 * *$ & $0.293 * *$ & $0.403 * *$ & & \\
\hline 5) Well-being & $0.242^{* *}$ & $0.253^{* *}$ & $0.209 * *$ & $0.296 * *$ & \\
\hline Mean (SD) & $21.53(3.78)$ & $12.27(7.15)$ & $12.09(3.50)$ & $11.25(3.26)$ & $59.77(23.5 \mathrm{I})$ \\
\hline
\end{tabular}

Note: $* * p<0.01$.

Abbreviation: SD, standard deviation.

married. Table 1 presents means, standard deviations, and zero-order correlations between measurement variables. As expected, social cohesion was significantly associated with social embeddedness $(r[1880]=0.24 ; P<0.01)$. In addition, social embeddedness was significantly contributed to tangible support $(r[1880]=0.16 ; P<0.01)$ and emotional support $(r[1880]=0.29 ; P<0.01)$. Statistically significant positive associations were also found between well-being and social cohesion $(r[1880]=0.24 ; P<0.01)$ and social embeddedness $(r[1880]=0.25 ; P<0.01)$.

Figure 2 shows the structural equations model used to test the proposed mediational model. The model fit was evaluated using maximum likelihood estimation. Testing the model yielded a good fit to the data $\left(\chi^{2} /\right.$ degree of freedom $[\mathrm{df}]=5.75$; $\mathrm{GFI}=0.98$; $\mathrm{CFI}=0.98$; RMSEA $=0.05$; PCLOSE $=0.45$ ). Factor loadings on the construct of social cohesion ranged from $0.62-0.88$. Factor loadings on the construct of well-being ranged from $0.67-0.84$, which indicated that the constructs were relatively well-defined. Regarding the processes connecting social cohesion to well-being, the study proposed that social embeddedness significantly mediates the effect of social cohesion upon well-being through two pathways. It was hypothesized that social cohesion leads to increased social embeddedness, which may contribute to inducing tangible support and emotional support, which consequently affect well-being. As shown in Table 2, the SEM findings revealed that social cohesion is significantly associated with social embeddedness (critical ratio $[\mathrm{CR}]=10.45 ; P<0.001$ ). It was also found that social embeddedness is significantly contributed to tangible support and emotional support. Consequently, tangible support $(\mathrm{CR}=4.37 ; P<0.001)$ and emotional support ( $\mathrm{CR}=7.31 ; P<0.001)$ were significantly associated with well-being. The total effect of social cohesion on well-being, which includes both mediating and direct effects, was significant $(\beta=0.23 ; P<0.001)$. The mediated effect of social cohesion, through social embeddedness, on well-being was found to be 0.06 . This indicates that slightly more than one-fourth of the total effect of social cohesion on well-being is mediated through social embeddedness. Additionally, about $32 \%$ of the total effect of social embeddedness on well-being was mediated by tangible support and emotional support $(\beta=0.22 ; P<0.001)$.

In the next step of analysis, a bootstrapping method was used to make conclusions about the significance of indirect effects of social cohesion through social embeddedness, tangible support, and emotional support towards well-being. The finding of the bootstrapping analysis revealed that the impact of social cohesion is significantly mediated by social embeddedness $(P<0.001)$. In addition, tangible support and emotional support also significantly mediated the effect of

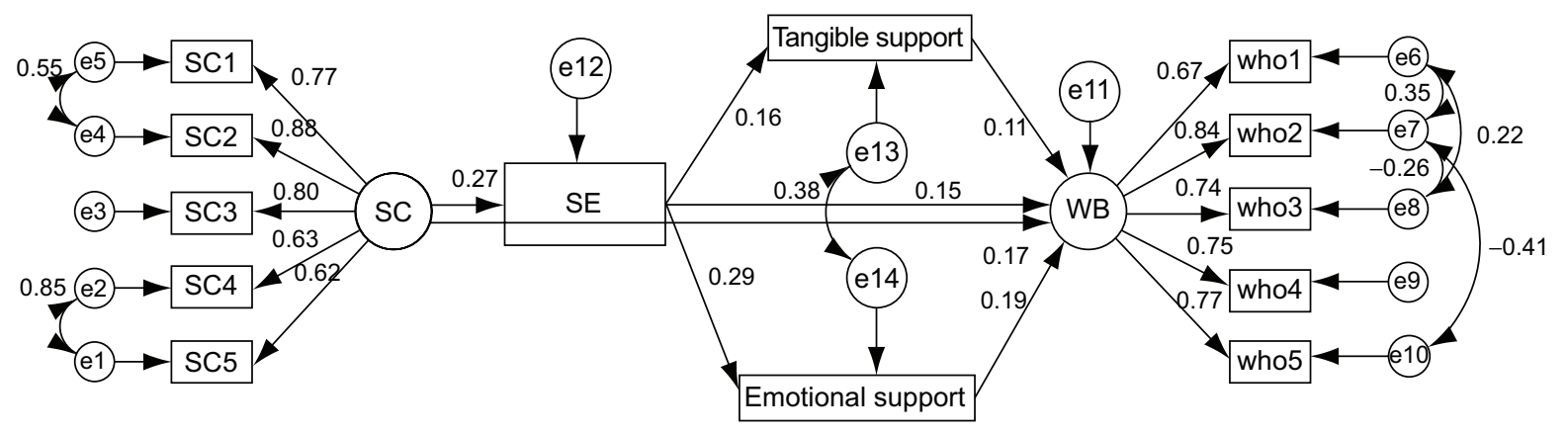

Figure 2 SEM model with standardized regression weights.

Notes: $\mathrm{CMIN} / \mathrm{DF}=5.755 ; \mathrm{RMSEA}=0.050 ; \mathrm{PCLOSE}=0.452 ; \mathrm{GFI}=0.975 ; \mathrm{AGFI}=0.958 ; \mathrm{CFI}=0.98 \mathrm{I} ; \mathrm{TLI}=0.973$.

Abbreviations: SEM, structural equation modeling; SC, social cohesion; SE, social embeddedness; WB, well-being; CMIN/DF, minimum discrepancy divided by degrees of freedom; RMSEA, root mean square error of approximation; PCLOSE, p-value for test of close fit; GFI, goodness of fit index; AGFI, adjusted goodness of fit index; CFI, comparative fix index; TLI, Tucker-Lewis coefficient. 
Table 2 The results of SEM

\begin{tabular}{|c|c|c|c|c|c|c|c|c|}
\hline \multirow[t]{2}{*}{ Path } & \multirow[t]{2}{*}{ Estimate } & \multirow[t]{2}{*}{ SE } & \multirow[t]{2}{*}{ CR } & \multirow[t]{2}{*}{ Beta } & \multicolumn{2}{|l|}{ Effect } & \multicolumn{2}{|c|}{ Bounds (BC) } \\
\hline & & & & & Total & Indirect & Lower & Upper \\
\hline Social cohesion $\rightarrow$ social embeddedness & 3.30 & 0.32 & $10.46 * * *$ & 0.27 & 0.27 & & & \\
\hline Social embeddedness $\rightarrow$ tangible support & 0.08 & 0.01 & $7.01 * * *$ & 0.16 & 0.16 & & & \\
\hline Social embeddedness $\rightarrow$ emotional support & 0.13 & 0.01 & $13.30 * * *$ & 0.29 & 0.29 & & & \\
\hline Tangible support $\rightarrow$ well-being & 0.03 & 0.01 & $4.37^{* * *}$ & 0.11 & 0.11 & & & \\
\hline Social embeddedness $\rightarrow$ well-being & 0.02 & 0.00 & $5.98 * * *$ & 0.15 & 0.22 & 0.07 & 0.058 & 0.092 \\
\hline Social cohesion $\rightarrow$ well-being & 0.28 & 0.04 & $6.64 * * *$ & 0.17 & 0.23 & 0.06 & 0.043 & 0.078 \\
\hline Emotional support $\rightarrow$ well-being & 0.06 & 0.01 & $7.31 * * *$ & 0.19 & 0.19 & & & \\
\hline
\end{tabular}

Note: $* * * P<0.001$

Abbreviations: SEM, structural equation modeling; SE, standard error; CR, critical ratio; BC, bias-corrected confidence interval.

social embeddedness on well-being $(P<0.001)$. Finally the Sobel test confirmed that social embeddedness significantly mediated the effect of social cohesion on well-being $(\mathrm{Z}=5.62$; $P<0.001)$. In addition, results of other Sobel tests indicated that the effect of social embeddedness is mediated by tangible support $(\mathrm{Z}=3.58 ; P<0.001)$ and emotional support $(\mathrm{Z}=6.78$; $P<0.001)$.

\section{Moderating effect of gender}

Finally, following Byrne's guidelines, ${ }^{33}$ a multigroup analysis test of the full mediation model was conducted, to determine whether the path coefficient for the relationships between social cohesion and well-being were equal in both groups (ie, older men and women). Using SPSS Amos software, the multigroup option was employed, to determine any significant differences in structural parameters between older males and older females. The first step of the analysis involved testing the baseline model for the two groups. Therefore, the validated structural path model was examined across two groups (older men and women) considered collectively - without any equality-constrained relationship across two groups. Figure 3 and Figure 4 show the tested model, indicating good fit between the data and the model $\left(\chi^{2}=383.21 ; P<0.001\right.$; $\mathrm{df}=108, \chi^{2} / \mathrm{df}=3.55 ; \mathrm{GFI}=0.97 ; \mathrm{CFI}=0.98 ; \mathrm{RMSEA}=0.037$, PCLOSE $=1.00$ ). The chi-square and degree of freedom yielded from the unconstrained model were compared to the particular constrained path. The result of the chi-square difference comparison provided significant difference between male and female groups in the relationship between social cohesion and well-being, suggesting that social cohesion affects well-being through a social embeddedness mechanism differently, according to gender.

\section{Discussion}

Findings from the current population-based study are in accordance with a growing body of literature ${ }^{2,9,11,34}$ that supports the importance of neighborhood social cohesion for the well-being of older adults. In other words, this result supports the notion that enhancing well-being in older adults should not only rely on improvement of the individuals' characteristics, but should also consider the contexts of the social environment. ${ }^{4,23,35,36}$

Regarding the most important goal of this paper - to elucidate how social cohesion may affect well-being of older adults - a theoretical model was proposed and tested. The findings showed that the impact of social cohesion

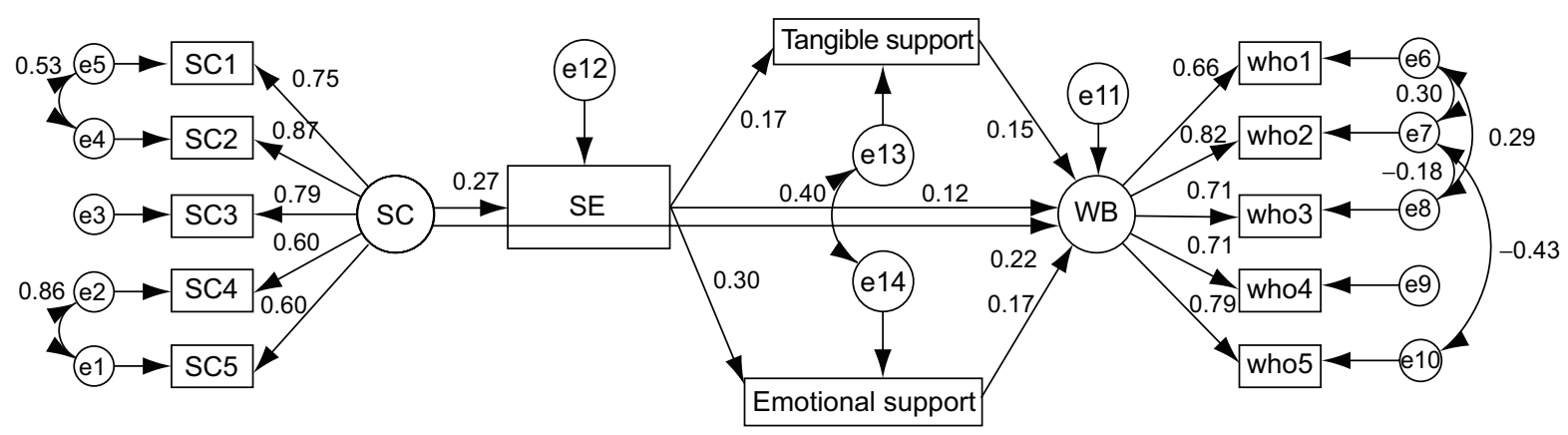

Figure 3 SEM model with standardized regression weights for male respondents.

Notes: $\mathrm{CMIN} / \mathrm{DF}=3.548 ; \mathrm{RMSEA}=0.037$; PCLOSE $=\mathrm{I} .000 ; \mathrm{GFI}=0.970 ; \mathrm{AGFI}=0.949 ; \mathrm{CFI}=0.980 ; \mathrm{TLI}=0.970$.

Abbreviations: SEM, structural equation modeling; SC, social cohesion; SE, social embeddedness; WB, well-being; CMIN/DF, minimum discrepancy divided by degrees of freedom; RMSEA, root mean square error of approximation; PCLOSE, p-value for test of close fit; GFI, goodness of fit index; AGFI, adjusted goodness of fit index; CFI, comparative fix index; TLI, Tucker-Lewis coefficient. 


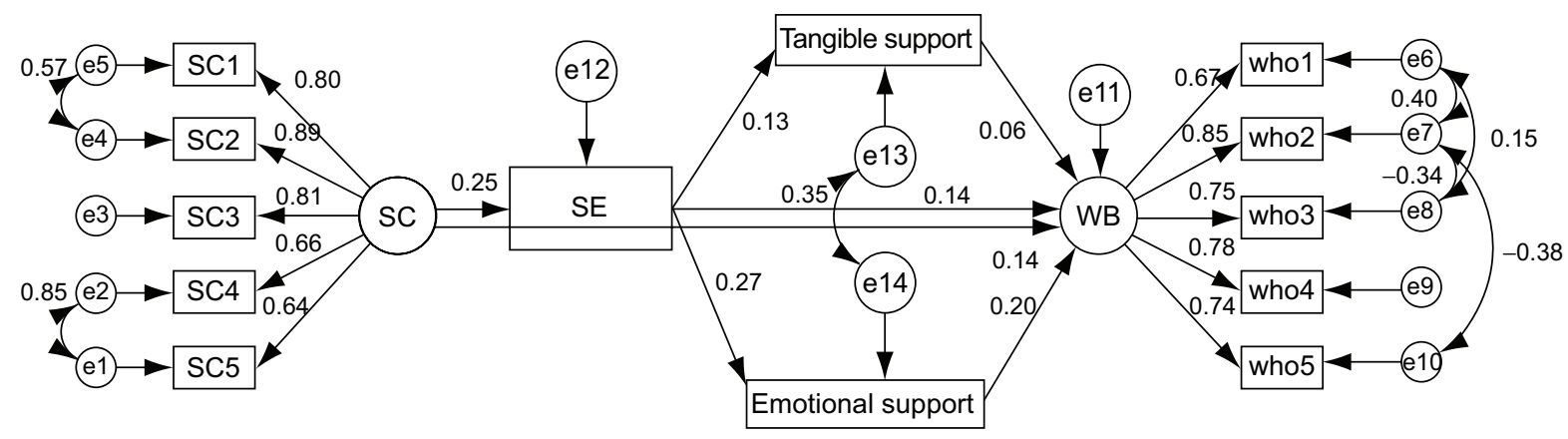

Figure 4 SEM model with standardized regression weights for female respondents.

Notes: $\mathrm{CMIN} / \mathrm{DF}=3.548 ; \mathrm{RMSEA}=0.037$; PCLOSE $=1.000 ; \mathrm{GFI}=0.970 ; \mathrm{AGFI}=0.949 ; \mathrm{CFI}=0.980 ; \mathrm{TLI}=0.970$.

Abbreviations: SEM, structural equation modeling; SC, social cohesion; SE, social embeddedness; WB, well-being; CMIN/DF, minimum discrepancy divided by degrees of freedom; RMSEA, root mean square error of approximation; PCLOSE, p-value for test of close fit; GFI, goodness of fit index; AGFI, adjusted goodness of fit index; CFI, comparative fix index; TLI, Tucker-Lewis coefficient.

is significantly mediated through a social embeddedness mechanism, wherein social cohesion significantly affects social embeddedness and consequently affects well-being through tangible support and emotional support. This study's findings supported the proposed theoretical model, which speculated that the socially-cohesive neighborhood might lead to a tightly-knit community, which would increase supportive relations. Increased supportive relations induce more tangible and emotional support, which results in greater well-being. The findings showed that social cohesion leads to higher degrees of social embeddedness, resulting in the provision of higher levels of tangible support and emotional support to neighbors, in times of sickness and for help with household tasks. Consequently, it results in greater levels of well-being in older adults.

The third hypothesis - which postulated that the association between social cohesion and well-being is moderated by gender - was supported. The finding of the multigroup analysis showed that a social embeddedness mechanism mediates the impact of social cohesion on well-being through two pathways: tangible support and emotional support, which differ for men and women. According to the social embeddedness mechanism, social cohesion mostly contributes to greater levels of well-being in men through tangible support. However, for women, the positive impact of social cohesion on well-being is substantially mediated through emotional support. These findings are in line with some previous studies, which have found that the association between social support and health status differs according to gender. ${ }^{37,38}$ Our findings are also supported by studies that highlight the more important role of emotional support towards well-being and health in older women than in men. ${ }^{17,39}$ Moreover, it was found that the mediating effect of tangible support on the association between social cohesion and well-being was considerably greater among men. This finding is consistent with the results of studies that show the more important role of tangible support toward health for men than for women. ${ }^{40}$ Older men (compared to women) are more likely to benefit from tangible support, whereas older women gain advantage through emotional support from their social environment. This premise is supported by studies which found that older men were at risk of experiencing unmet needs when there is a lack of tangible support for their physical care. ${ }^{41}$ However, among older women, greater levels of emotional support are found to be important in reducing depression and boosting psychological well-being. ${ }^{17,39}$ This study adds that increased

Table 3 Summary of multigroup analysis

\begin{tabular}{|c|c|c|c|c|c|c|c|c|c|}
\hline \multirow[t]{2}{*}{ Path } & \multicolumn{4}{|l|}{ Male } & \multicolumn{4}{|l|}{ Female } & \multirow[t]{2}{*}{$\Delta \lambda^{2} / d f^{a}$} \\
\hline & Estimate & SE & CR & Beta & Estimate & SE & CR & Beta & \\
\hline Social cohesion $\rightarrow$ social embeddedness & 3.51 & 0.49 & $7.17 * * *$ & 0.27 & 2.95 & 0.40 & $7.33 * * *$ & 0.25 & $54.13^{* * *}$ \\
\hline Social embeddedness $\rightarrow$ tangible support & 0.08 & 0.02 & $5.20 * * *$ & 0.17 & 0.06 & 0.02 & $4.07 * * *$ & 0.13 & $2880.92 * * *$ \\
\hline Social embeddedness $\rightarrow$ emotional support & 0.14 & 0.02 & $9.31 * * *$ & 0.3 & 0.12 & 0.01 & $8.92 * * *$ & 0.27 & $2991.53 * * *$ \\
\hline Tangible support $\rightarrow$ well-being & 0.04 & 0.01 & $4.25^{* * *}$ & 0.16 & 0.02 & 0.01 & $1.65^{\dagger}$ & 0.06 & $3676.90 * * *$ \\
\hline Social embeddedness $\rightarrow$ well-being & 0.02 & 0.01 & $3.45^{* * *}$ & 0.12 & 0.02 & 0.01 & $4.07 * * *$ & 0.14 & $1996.76 * * *$ \\
\hline Social cohesion $\rightarrow$ well-being & 0.36 & 0.07 & $5.49 * * *$ & 0.22 & 0.22 & 0.06 & $3.85 * * *$ & 0.14 & $161.69 * * *$ \\
\hline Emotional support $\rightarrow$ well-being & 0.05 & 0.01 & $4.4 I^{* * * *}$ & 0.17 & 0.06 & 0.01 & $5.72 * * *$ & 0.20 & $3216.78 * * *$ \\
\hline
\end{tabular}

Notes: a Chi-square and degree of freedom values for corresponding constrained relationship. $* * * P<0.001$. ${ }^{t} P<0.1$.

Abbreviations: SE, standard error; CR, critical ratio. 
social embeddedness resulting from social cohesion induces more tangible support for men and emotional support for women. Additionally, this finding is in agreement with the finding of Wellman and Wortley: that men are unlikely to get emotional support from friends, and that they rely on family, rather than friends, to obtain emotional support. ${ }^{42}$

\section{Limitations of the study}

Although the results of the present study provide useful information, there are some limitations which deserve attention. First, the most serious limitation of the study is its reliance on cross-sectional design. Consequently, the possibility that greater levels of well-being cause older adults to have more interaction with others and perceive their neighbors in a more positive light cannot be ruled out. Therefore, future use of longitudinal studies is needed to confirm the proposed model. The second limitation to be addressed is the use of a self-reporting method for data gathering, which may result in response bias. ${ }^{43}$ Since some methodological texts suggest the importance of using longitudinal data for mediation analysis, to avoid model bias, ${ }^{44,45}$ the final concern that should be addressed is the use of cross-sectional data for mediation analysis. However, it is important to mention that mediation analysis can also be conducted using cross-sectional observations. ${ }^{46,47}$

\section{Conclusion}

In this study, social embeddedness was theorized as a potential mechanism linking neighborhood social cohesion to wellbeing. In addition to highlighting the importance of social cohesion in neighborhoods for the well-being of older adults, the current study provides evidence to support the function of social embeddedness as a mechanism, linking social cohesion to well-being through tangible and emotional supports. Therefore, social and health policymakers should design and implement interventions, such as revitalizing neighborhoods ${ }^{48}$ and developing interventions curriculums, targeting older adults, ${ }^{49,50}$ to promote social cohesion, which may, consequently, result in greater levels of well-being for older adults.

\section{Acknowledgments}

The survey was supported by The Ministry of Science, Technology and Innovation (Malaysia), under Science Fund Grant No. 04-01-04-SF0479.

\section{Disclosure}

The authors report no conflicts of interest in relation to this work.

\section{References}

1. Momtaz YA, Hamid TA, Yusoff S, et al. Loneliness as a risk factor for hypertension in later life. J Aging Health. 2012;24(4):696-710.

2. Cramm JM, van Dijk HM, Nieboer AP. The importance of neighborhood social cohesion and social capital for the well being of older adults in the community. Gerontologist. 2013;53(1):142-152.

3. Momtaz YA, Ibrahim R, Hamid TA, Yahaya N. Sociodemographic predictors of elderly's psychological well-being in Malaysia. Aging Ment Health. 2011;15(4):437-445.

4. Chumbler NR, Leech T. The impact of neighborhood cohesion on older individuals' self-rated health status. In: Kronenfeld JJ, editor. Social determinants, health disparities and linkages to health and health care. Bingley, UK: Emerald Group Publishing; 2013:41-55.

5. Harpham T, Grant E, Thomas E. Measuring social capital within health surveys: key issues. Health Policy Plan. 2002;17(1):106-111.

6. Fone D, Dunstan F, Lloyd K, Williams G, Watkins J, Palmer S. Does social cohesion modify the association between area income deprivation and mental health? A multilevel analysis. Int J Epidemiol. 2007;36(2):338-345.

7. Fisher KJ, Li F, Michael Y, Cleveland M. Neighborhood-level influences on physical activity among older adults: a multilevel analysis. $J$ Aging Phys Act. 2004;12(1):45-63.

8. Colletta NJ, Lim TG, Kelles-Viitanen A, editors. Social cohesion and conflict prevention in Asia: Managing diversity through development. Washington, DC: The World Bank; 2001.

9. Cagney KA, Browning CR, Wen M. Racial disparities in self-rated health at older ages: what difference does the neighborhood make? J Gerontol B Psychol Sci Soc Sci. 2005;60(4):S181-S190.

10. Clark CJ, Guo H, Lunos S, et al. Neighborhood cohesion is associated with reduced risk of stroke mortality. Stroke. 2011;42(5):1212-1217.

11. Inoue S, Yorifuji T, Takao S, Doi H, Kawachi I. Social cohesion and mortality: a survival analysis of older adults in Japan. Am J Public Health. 2013;103(12):e60-e66.

12. Stafford M, Mcmunn A, De Vogli R. Neighbourhood social environment and depressive symptoms in mid-life and beyond. Ageing Soc. 2011;31(6):893-910.

13. Mair C, Diez Roux AV, Galea S. Are neighbourhood characteristics associated with depressive symptoms? A review of evidence. J Epidemiol Community Health. 2008;62(11):940-946.

14. Kubzansky LD, Subramanian SV, Kawachi I, Fay ME, Soobader MJ, Berkman LF. Neighborhood contextual influences on depressive symptoms in the elderly. Am J Epidemiol. 2005;162(3):253-260.

15. Mohnen SM, Groenewegen PP, Volker B, Flap H. Neighborhood social capital and individual health. Soc Sci Med. 2011;72(5):660-667.

16. Schmitz MF, Giunta N, Parikh NS, Chen KK, Fahs MC, Gallo WT. The association between neighbourhood social cohesion and hypertension management strategies in older adults. Age Ageing. 2012;41(3): 388-392.

17. Kendler KS, Myers J, Prescott CA. Sex differences in the relationship between social support and risk for major depression: a longitudinal study of opposite-sex twin pairs. Am J Psychiatry. 2005;162(2):250-256.

18. Belle D. Gender differences in the social moderators of stress. In: Barnett RC, Biener L, Baruch GK, editors. Gender and stress. New York: Free Press; 1987:257-277.

19. Fuhrer R, Stansfeld SA. How gender affects patterns of social relations and their impact on health: a comparison of one or multiple sources of support from "close persons". Soc Sci Med. 2002;54(5):811-825.

20. Mujahid MS, Diez Roux, Morenoff JD, et al. Neighborhood characteristics and hypertension. Epidemiology. 2008;19(4):590-598.

21. Barrera M. Distinctions between social support concepts, measures, and models. Am J Community Psychol. 1986;14(4):413-445.

22. Moody J, White DR. Structural cohesion and embeddedness: a hierarchical concept of social groups. Am Sociol Rev. 2003;68(1):103-127.

23. Bromell L, Cagney KA. Companionship in the neighborhood context older adults' living arrangements and perceptions of social cohesion. Res Aging. 2014;36(2):228-243. 
24. Momtaz YA, Hamid TA, Yahaya N. The role of religiosity on relationship between chronic health problems and psychological well-being among Malay Muslim older persons. Res J Med Sci. 2009;3(6):188-193.

25. Momtaz YA, Hamid TA, Ibrahim R, Yahaya N, Chai ST. Moderating effect of religiosity on the relationship between social isolation and psychological well-being. Ment Health Relig Cult. 2011;14(2):141-156.

26. Sampson RJ, Raudenbush SW, Earls F. Neighborhoods and violent crime: a multilevel study of collective efficacy. Science. 1997;277(5328): 918-924.

27. Bech P, Olsen LR, Kjoller M, Rasmussen NK. Measuring well-being rather than the absence of distress symptoms: a comparison of the SF-36 Mental Health subscale and the WHO-Five Well-Being Scale. Int J Methods Psychiatr Res. 2003;12(2):85-91.

28. Momtaz YA, Ibrahim R, Hamid TA, Yahaya N. Mediating effects of social and personal religiosity on the psychological well being of widowed elderly people. OMEGA (Westport). 2010;61(2):145-162.

29. Siedlecki KL, Salthouse TA, Oishi S, Jeswani S. The relationship between social support and subjective well-being across age. Soc Indic Res. 2014;117(2):561-576.

30. Sherbourne CD, Stewart AL. The MOS social support survey. Soc Sci Med. 1991;32(6):705-714.

31. Shrout PE, Bolger N. Mediation in experimental and nonexperimental studies: new procedures and recommendations. Psychol Methods. 2002; 7(4):422-445.

32. MacKinnon DP, Lockwood CM, Hoffman JM, West SG, Sheets V. A comparison of methods to test mediation and other intervening variable effects. Psychol Methods. 2002;7(1):83-104.

33. Byrne BM. Testing for multigroup invariance using AMOS graphics: a road less traveled. Struct Eq Modeling. 2004;11(2):272-300.

34. Browning CR, Cagney KA. Neighborhood structural disadvantage, collective efficacy, and self-rated physical health in an urban setting. J Health Soc Behav. 2002;43(4):383-399.

35. Bjornstrom EE, Ralston ML, Kuhl DC. Social cohesion and self-rated health: the moderating effect of neighborhood physical disorder. Am J Community Psychol. 2013;52(3-4):302-312.

36. Yip W, Subramanian SV, Mitchell AD, Lee DT, Wang J, Kawachi I. Does social capital enhance health and well-being? Evidence from rural China. Soc Sci Med. 2007;64(1):35-49.
37. Caetano S, Silva C, Vettore M. Gender differences in the association of perceived social support and social network with self-rated health status among older adults: a population-based study in Brazil. $B M C$ Geriatr. 2013;13(1):122.

38. Okamoto K, Tanaka Y. Gender differences in the relationship between social support and subjective health among elderly persons in Japan. Prev Med. 2004;38(3):318-322.

39. Fuhrer R, Stansfeld SA, Chemali J, Shipley MJ. Gender, social relations and mental health: prospective findings from an occupational cohort (Whitehall II study). Soc Sci Med. 1999;48(1):77-87.

40. Grav S, Hellzen O, Romild U, Stordal E. Association between social support and depression in the general population: the HUNT study, a cross-sectional survey. J Clin Nurs. 2012;21(1-2):111-120.

41. Momtaz YA, Hamid TA, Ibrahim R. Unmet needs among disabled elderly Malaysians. Soc Sci Med. 2012;75(5):859-863.

42. Wellman B, Wortley S. Brothers' keepers: Situating kinship relations in broader networks of social support. Sociol Perspect. 1989;23(3): 273-306.

43. Podsakoff PM, MacKenzie SB, Lee JY, Podsakoff NP. Common method biases in behavioral research: a critical review of the literature and recommended remedies. J Appl Psychol. 2003;88(5):879-903.

44. Maxwell SE, Cole DA. Bias in cross-sectional analyses of longitudinal mediation. Psychol Methods. 2007;12(1):23-44.

45. Maxwell SE, Cole DA, Mitchell MA. Bias in cross-sectional analyses of longitudinal mediation: Partial and complete mediation under an autoregressive model. Multivariate Behav Res. 2011;46(5):816-841.

46. Lei PW, Wu Q. Introduction to structural equation modeling: issues and practical considerations. Educ Meas. 2007;26(3):33-43.

47. Lockwood CM, DeFrancesco CA, Elliot DL, Beresford SAA, Toobert DJ. Mediation analyses: applications in nutrition research and reading the literature. J Am Diet Assoc. 2010;110(5):753-762.

48. Brown B, Perkins DD, Brown G. Place attachment in a revitalizing neighborhood: individual and block levels of analysis. J Env Psychol. 2003;23(3):259-271

49. King E, Samii C, Snilstveit B. Interventions to promote social cohesion in sub-Saharan Africa. J Dev Effect. 2010;2(3):336-370.

50. Easterly W, Ritzan J, Woolcock M. Social cohesion, institutions, and growth. Econ Polit-Oxford. 2006;18(2):103-120.
Clinical Interventions in Aging

\section{Publish your work in this journal}

Clinical Interventions in Aging is an international, peer-reviewed journal focusing on evidence-based reports on the value or lack thereof of treatments intended to prevent or delay the onset of maladaptive correlates of aging in human beings. This journal is indexed on PubMed Central, MedLine,

\section{Dovepress}

CAS, Scopus and the Elsevier Bibliographic databases. The manuscript management system is completely online and includes a very quick and fair peer-review system, which is all easy to use. Visit http://www.dovepress. com/testimonials.php to read real quotes from published authors. 